\title{
Ação política e pensamento político de Golbery do Couto e Silva
}

Andressa Patacho Cafarelli ${ }^{1}$

\section{Resumo}

Este trabalho analisa o pensamento político e ação política de Golbery do Couto e Silva por meio da análise de obras secundárias, além de utilizar como fontes documentos oficiais e jornais da época. O objetivo é entender e analisar a trajetória política de Golbery e sistematizar as ideias formuladas por ele a partir de uma pesquisa bibliográfica. Tal estudo busca compreender a atuação do ator político nos preparativos do golpe militar de 1964 através do Instituto de Pesquisas e Estudos Sociais- e durante o período da Ditadura Militar (1964-1985), principalmente sua forte atuação nos governos do General Castelo Branco, do general Ernesto Geisel e do general João Baptista Figueiredo.

Palavras-chave: Pensamento Político Brasileiro; Golbery do Couto e Silva; Pensamento Militar; Regime Militar.

\begin{abstract}
This paper analyzes the political thinking and political action of Golbery do Couto e Silva through the analysis of secondary works, as well as using official documents and newspapers from that time. The objective is to understand and analyze Golbery's political trajectory and to systematize the ideas formulated by Golbery from a bibliographical research. This study seeks to understand the role of the political actor in the preparations for the 1964 military coup - through the Institute for Research and Social Studies - and during the period of the Military Dictatorship (1964-1985), mainly it's strong role in the governments of General Castelo Branco, General Ernesto Geisel and General João Baptista Figueiredo.
\end{abstract}

Keywords: Brazilian Political Thought; Golbery do Couto e Silva; Military Thinking; Military Regime.

1 Mestranda do programa de pós-graduação em Ciências Sociais pela Universidade Federal de São Paulo. E-mail: andressa.cafarelli@gmail.com 


\section{Introdução}

A figura de Golbery do Couto e Silva sempre foi cercada de uma aura enigmática. Não à toa era visto como "eminência parda" do governo Geisel, onde teve forte atuação. Golbery atuava nos bastidores do poder, fazendo parte do corpo burocrático. Luiz Alves afirma que algumas figuras, como a do nosso ator,

Forneceram o estofo ideológico às ações de quem efetivamente está ocupando o poder, sem, no entanto, tornar isso tão evidente. Apesar de procederem em circunspecção na vida pública procuravam registrar suas reflexões em livros, artigos, ensaios, etc.; a fim de consubstanciar suas teses e eventualmente lançá-las ao debate (ALVES; 2011)

Golbery atuou no interior da "máquina pública", e nesse contexto, agia como um orientador político de seu respectivo mandatário. Esse fato lhe permitiu uma maior efetividade na participação dos rumos das políticas implantadas no Brasil durante o período. O "Bruxo", como se refere a ele Elio Gaspari em suas obras sobre a Ditadura Militar (GASPARI, 2002 e 2009), foi figura central na montagem do regime e de sua estrutura. Nesse contexto:

A escolha do objeto - o pensamento de Golbery do Couto e Silva permite uma reflexão sobre as bases teóricas do regime militar brasileiro. Nesse sentido, justifica-se tanto em termos mais amplos - a necessidade de se estudar um período da história brasileira que até hoje impacta a sociedade e a política do país - como em termos mais estritos: investigar os pressupostos teóricos que sustentavam o regime militar, em que ideais se ancorava e propagava (CAFARELLI; 2017)

\section{Golbery do Couto e Silva: ator político pré-1964}

O general nasceu em 21 de agosto de 1911, ingressou na Escola Militar de Realengo em 1927. Participou da Revolução de 30 e combateu a revolução constitucionalista de 1932. No ano de 1937, Golbery passou pela diretoria de material bélico e pela secretaria geral do Conselho de Segurança Nacional. Além disso, em 1941 participou do curso de Estadomaior e, em 1944 participou do curso intensivo do Estado-Maior norte americano, depois 
foi para a Itália integrando a Força Expedicionária Brasileira (FEB) e, em 1947, foi designado para a Comissão Militar do Paraguai.

Golbery foi promovido a tenente-coronel e alocado na Seção de Informações do Estado-Maior do Exército (EME) em 1951; apenas em 1952 ele entra na Escola Superior de Guerra (criada em 1949). Em 1954 escreve o "Manifesto dos Generais", no qual se pede a renúncia de Vargas - e foi preso em 1955 por conta da conspiração. Em 1956 é promovido a coronel e vai para a seção de operações do EME. Continuando sua trajetória, em 1959 oferece apoio à campanha de Jânio Quadros, que acaba vitorioso. Em 1960, com a posse do novo presidente, assume a chefia da Seção de Operações do Estado-Maior das Forças Armadas (EMFA), e no mesmo ano recusa o convite para a Secretaria de Segurança do Rio.

No entanto, a renúncia do mandatário também abala a carreira de Golbery que participa novamente da redação de um manifesto - dos ministros militares - que oferecem um veto ao retorno e posse do vice João Goulart. A derrota no projeto de impedimento do vice torna a vida de Golbery mais difícil no Exército e, em 1961, Golbery perde o cargo que possuía no Conselho de Segurança Nacional - que tem sob suas ordens o Serviço Federal de Informações e Contra Informações (SFICI) - abandonando o projeto de criação de um sistema de segurança interna que unificaria os aparelhos policiais civis e militares. Em setembro foi exonerado do Conselho de Segurança Nacional e transferido para a Paraíba, em função obscura, pedindo para passar à reserva logo depois.

Retomando a vida civil trabalha no Instituto de Pesquisas e Estudos Sociais (IPÊS) - organização fundamental no que diz respeito à articulação civil que levou ao golpe de 1964. No IPÊS contribui para a montagem de uma “máquina de informações”, organizando um fichário que acabou servindo de base de dados para o futuro Serviço Nacional de Informações (SNI) - fichário esse que, por sua vez, tem por base os dados coletados ainda em 1961, quando Golbery tinha sob sua tutela o SFICI.

\subsection{A Escola Superior de Guerra}

A Escola Superior de Guerra (ESG) foi criada através de um decreto em 1948. Inspirou-se na National War College, localizada em Washington, EUA, porém precisava levar em conta as particularidades da sua nação, a qual deveria ter como prioritária a 
formação de uma elite que fosse capaz de resolver os problemas nacionais também em tempos de paz. Surgiu a partir de uma preocupação da alta hierarquia militar brasileira com relação à questão da segurança nacional. A ESG possuía uma visão econômica que tinha elementos liberais, valorizando a iniciativa privada, e também um posicionamento próamericanista diante do mundo bipolar, além de defender o fortalecimento do Executivo e a centralização do poder. Sendo assim, ela era produto do interesse da cúpula militar em aprimorar intelectualmente os oficiais superiores, e também dos ministros, de manter afastados dos importantes cargos do Estado-maior e do comando da tropa os oficiais considerados pouco confiáveis.

O corpo permanente da escola era composto através de nomeações do Presidente da República. Entre os generais que apresentaram grande relevância e influência na constituição da ESG estão Golbery do Couto e Silva, Orlando Geisel, Ernesto Geisel e Jurandir de Bizarria Mamede. Os militares produziram importantes escritos e reflexões acerca das questões de ordem política, social, econômica e militar; além de terem elaborado a Doutrina de Segurança Nacional (DSN).

A Escola Superior de Guerra foi responsável pela atualização dos conceitos gerais de estratégia no Brasil, substituindo o antigo conceito de defesa pelo de segurança nacional; nesse contexto, a escola produziu conceitos como planejamento de segurança nacional e conceito estratégico nacional. A ESG se propunha a realizar a sistematização de debates dos problemas do país e oferecia-se também como centro de estudos para uma crise universal, ela partia da mesma premissa de que o subdesenvolvimento brasileiro era produto da falta de articulação e competência de sua elite (BONFADA, 2010).

\subsection{A Doutrina de Segurança Nacional}

Golbery do Couto e foi um dos formuladores da Doutrina de Segurança Nacional, a qual é considerada a base ideológica do regime militar (1964-1985)². No período havia uma grande incerteza com relação a quem poderia estabelecer a segurança nacional, sendo colocado o Estado como a única força hegemônica capaz de fazer isso. Nesse contexto, a DSN equivale a uma doutrina de segurança do Estado.

\footnotetext{
2 Já para Elio Gaspari (2002), a DSN ou “ideologia de segurança nacional” não chegou a ter o status de doutrina, foi antes uma ideia que contribuiu para racionalizar a brutalização da política ao longo dos regimes militares.
} 
No período designado, os países da América Latina estavam substituindo o princípio de defesa coletiva do hemisfério pelo princípio de segurança interna. E é esse princípio que vai nortear as ditaduras civil-militares espalhadas pelo continente americano durante as décadas de 1960 e 1970, que tiveram como base de suas diretrizes a questão da necessidade da segurança nacional. No Brasil é formulada a Doutrina de Segurança Nacional, seus principais conceitos são a ideia de inimigo interno e a ideia de fronteiras ideológicas. Nesse contexto, a segurança nacional une a política interna e a política externa, não existe mais a separação. (FERNANDES, 2009).

\subsection{Instituto de Pesquisas e Estudos Sociais e o Golpe de 1964}

Segundo Oliveiros Ferreira (1988), os militares apresentavam-se, no contexto dos anos 60, como um grupo coeso e organizado, daí tendo certa proeminência na ação política. A liderança militar contou com apoio civil e internacional - direto dos EUA. A relação EUA/Brasil de certa maneira "esfriou" no governo João Goulart, mas se manteve "quente" com os militares e setores civis. Durante muitos anos duvidou-se da participação direta dos norte-americanos, mas recentemente documentos abertos nos EUA mostraram que a cooperação direta de fato ocorreu (a famosa Operação Brother Sam, por exemplo). Comprovou-se então que no que diz respeito ao golpe de 1964, a ação seria brasileira, porém o apoio logístico e diplomático ficaria a cargo dos EUA - o qual exigia um golpe de Estado com "ar de legalidade" (FICO, 2008).

Entre algumas parcelas civis houve um apoio explícito e direto no que se refere à ditadura civil militar ${ }^{3}$. Além de associações, empresários, religiosos (grande parte da cúpula da Igreja Católica), algumas instituições apresentam extrema importância no contexto, como o complexo IPÊS (Instituto de Pesquisas e Estudos Sociais) e IBAD (Instituto Brasileiro de Ação Democrática). Segundo Napolitano (2014) tal complexo dava o tom das críticas ao governo através da grande produção de materiais de propaganda negativa e da articulação dos diversos setores da sociedade que eram contra o trabalhismo e

\footnotetext{
${ }^{3}$ Existe uma ampla discussão acerca de qual seria a melhor definição para o período: Ditadura Militar ou Ditadura Civil-Militar. Abordarei na presente pesquisa como Ditadura Civil-Militar, seguindo a linha de alguns autores como Carlos Fico e René Dreifuss, uma vez que se comprovou a participação de civis na construção do golpe de 1964.
} 
anticomunistas: é importante enfatizar que tanto o IPÊS quanto o IBAD eram financiados pela Central Intelligence Agency (CIA) ${ }^{4}$.

Criado em 29 de novembro de 1961 e registrado em dezembro do mesmo ano, o IPÊS tem como data oficial de fundação apenas fevereiro de 1962. É importante notar que as "sementes" para sua construção são colocadas ainda durante o governo de Juscelino Kubitschek e a presidência de Jânio Quadros. Foi formado por militares da Escola Superior de Guerra, empresários e profissionais liberais de São Paulo e do Rio de Janeiro. O grupo apresentava como objetivo fazer oposição ao governo nacional-reformista de João Gourlart, era contrário ao alinhamento de forças sociais que apoiavam a sua administração, além disso, afirmava buscar soluções democráticas para os problemas do Brasil.

O IPÊS tinha uma “dupla vida" política, de um lado apoiava a reforma moderada das instituições políticas e econômicas existentes, e de outro coordenava uma campanha política/ideológica e militar.

Golbery do Couto e Silva trabalhou no IPÊS em 1962, quando monta uma máquina de informações e organiza o fichário visando ampliar o acervo que levou da época em que trabalhou no Serviço Federal de Informações e Contra-Informações (SFICI). Era responsável pelo Grupo de Levantamento de Conjuntura sobre as atividades de militantes da esquerda, ou seja, pelo monitoramento e controle das ações deles. O material possuía um levantamento de cerca de 4.000 brasileiros, o qual serviu mais tarde para o Serviço Nacional de Informações (SNI), criado por ele durante o governo Castello Branco. No IPÊS, Golbery fazia parte da estrutura formal de autoridades do Rio de Janeiro, apresentando funções no Grupo de Estudos e Ação (GEA), no Comitê Diretor (CD), no Comitê Executivo (CE) 5 , e no Conselho Orientador Nacional (CON).

O Grupo de Estudo e Ação (GEA), no qual Golbery apresentava funções, desenvolveu atividades de influência parlamentar que buscavam: a persuasão de legisladores; a manipulação da opinião pública; a montagem de uma frente antigoverno composta por frações econômicas e frações políticas da burguesia; uma tentativa de romper e penetrar ideologicamente organizações de classes trabalhadoras e movimento estudantil; uma tentativa de influenciar a Igreja e as Forças Armadas; a montagem de um corpo de

\footnotetext{
4 A CIA é uma agência de inteligência civil do governo dos Estados Unidos, responsável por investigar e fornecer informações de segurança nacional para os senadores de seu país.

5 Entre as funções do Comitê Executivo estão à tomada de decisão e programação das linhas gerais de ação dos objetivos do Ipês, a discussão e aprovação de projetos e orçamentos, e o controle das diretrizes políticas.
} 
doutrina e recomendações políticas, com a intenção de vir a se tornar um programa para o governo. A operação era realizada em dez principais áreas de ação política e ideológica: Forças Armadas, Congresso, Executivo, classe empresarial, sindicatos, classe camponesa, igreja, partidos políticos, mídia, camadas intermediárias.

Segundo Dreifuss (1981), o Grupo de Opinião Pública (GOP) era responsável pela manipulação da opinião pública por todos os meios disponíveis - imprensa falada e escrita. Esse programa teve o esquema preparado por Golbery, que era Chefe Geral de Opinião Pública. A campanha do GOP girava em torno de desenvolver a penetração ideológica, neutralizar a oposição, postergar a organização política das classes trabalhadoras industriais, impedir a consolidação da posição nacional-reformista dentro das Forças Armadas, além de incentivar formação de favoráveis clivagens políticas e apoio ativo dentre o amplo público das classes médias.

O Grupo de Levantamento da Conjuntura (GLC), também denominado Grupo de Pesquisa, era do Rio de Janeiro. Apresentava como líder nacional até junho de 1964, o general Golbery do Couto e Silva. Tal grupo possuía como tarefas: acompanhar os acontecimentos políticos em todas as áreas e setores; avaliar/apurar e fazer estimativas com relação ao impacto político dos acontecimentos; esboçar/construir mudanças táticas para acompanhar a evolução de qualquer situação/acontecimento e influenciar seu processo; realizar o planejamento estratégico e de informações; preparar a elite orgânica para a ação; estabelecer os objetivos do Ipês de longo e curto alcance, A equipe de Golbery produzia os trabalhos táticos e estratégicos e fornecia as diretrizes, doutrina e projetos. (Dreifuss, 1981)

Existia uma ligação estrita entre a Escola Superior de Guerra e o Ipês, uma vez que havia ali uma contribuição para desenvolver uma interpretação civil-militar necessária à campanha do golpe.

\section{Golbery do Couto e Silva: ator político pós-1964}

Golbery teve um papel de destaque em dois governos pós-golpe de 1964, o governo do General Castello Branco (1964-1967) e do General Ernesto Geisel (1974-1979), nesse contexto, o mesmo encontra-se na construção e no desmonte da ditadura militar. $\mathrm{O}$ ator político criou e assumiu a chefia do referido SNI no governo Castello Branco. Após o término desse governo, retorna à vida civil e assume o cargo de presidente da empresa 
norte-americana Dow Química, instalada no Brasil. Tempos depois se desliga da empresa para retornar a vida pública e ao governo ao lado de Ernesto Geisel, onde é colocado para desenvolver funções puramente políticas, nesse contexto ele assume a posição de chefe do Gabinete Civil. Assume a Casa Civil também no governo Figueiredo, mas abandona o cargo em 1981.

\subsection{Governo Castelo Branco e o Serviço Nacional de Informações}

Após a vitória do movimento que instalou a ditadura civil militar no Brasil, em 1964, o marechal Castello Branco ascende e é colocado como Presidente da República. Nos dias que se seguiram ao golpe ficou explicito que os militares não possuíam um projeto político articulado para o médio/longo prazo. Nesse contexto não existia uma agenda consistente de reformas, apenas um consenso que os uniu para dar encaminhamento à intervenção: "o combate ao comunismo e a corrupção".

Porém o que se obteve foi o descumprimento da promessa de Castello no que diz respeito à breve permanência dos militares no poder, já que governaram por 20 anos. É importante notar que apesar de sua permanência, o regime militar não se colocava como definitivo, uma vez que assumir tal posição implicaria na abdicação do mínimo de legitimidade institucional, colocando-se cada vez mais como uma ditadura de fato. O autoritarismo que foi implantado em 1964 possuía dois objetivos, o primeiro era destruir uma elite política e intelectual reformista que estava cada vez mais fortificada no Estado; o segundo era cortar os eventuais laços organizativos entre essa elite política intelectual e os movimentos sociais de base popular. O que temos entre os anos de 1964 a 1968 é uma combinação de repressão seletiva e construção de uma ordem autoritária e centralista, uma vez que:

Até que uma nova ameaça pudesse servir de justificativa ao endurecimento da repressão, o governo militar tinha que equilibrar o frágil consenso golpista e a unidade militar, além de acalmar os cidadãos que não aderiram ao golpe, permitindo-lhes certa liberdade de expressão (NAPOLITANO, 2014, pp.71)

Alguns estudiosos da época (como Elio Gaspari) denominam o período do governo de Castello Branco como uma "ditabranda" - ou seja, uma ditadura amena ou não consolidada de fato. Porém, apesar de ser colocado como uma forte representação da 
"ditabranda" foi o construtor institucional do regime autoritário, uma vez que nele foram editados quatro Atos Institucionais ${ }^{6}$, foi decretada a Lei da Imprensa ${ }^{7}$ e a Nova Constituição ${ }^{8}$. Além disso, nesse período também instituíram 17 atos principais, 104 atos complementares e vários "decretos secretos". Ainda durante seu governo, em 1967 novos passos eram dados rumo à institucionalização do regime militar com a criação do Conselho de Segurança Nacional, o qual era amparado por uma nova Lei de Segurança Nacional substituindo a Lei de 1953. Nesse contexto, o governo de Castello foi o que mais cassou os direitos políticos e os mandatos parlamentares, além de ter estruturado as bases jurídicas do regime autoritário, visando uma ação política institucional e de longo prazo. Contrapondo a denominação de "ditabranda" houve inúmeras denúncias de torturas em instalações militares.

Golbery foi um dos conspiradores e ganhou notoriedade nacional no primeiro governo pós-golpe, sendo encarregado de criar o Serviço Nacional de Informações (SNI), em junho de 1964 - um dos órgãos mais importantes de informação e segurança do governo brasileiro durante o período da ditadura civil militar.

O SNI foi criado com a finalidade de organizar e coordenar em todo o território nacional as atividades de informação e contrainformação, em particular as que interessam à Segurança Nacional (ARQUIVO NACIONAL, 1990). O órgão era subordinado e respondia apenas ao Presidente da República, e suas principais competências incluíam o planejamento de informações estratégicas, o planejamento de informações de segurança interna e o planejamento da contrainformação.

Nesse contexto, o Serviço Nacional de Informações foi criado em 1964 com o propósito de ser um produtor de informações visando apoiar as decisões do Presidente da República, sofreu modificações em 1967, quando passa a ser usado como uma ampla rede de espionagem. Sendo assim, ele nunca se dispôs a ser um organismo politicamente neutro, o qual tinha como função apenas informar o presidente; mas funcionava como uma

\footnotetext{
${ }^{6} \mathrm{O}$ principal objetivo dos Atos Institucionais era garantir um reforço legal do Poder Executivo, e particularmente da Presidência da República, dentro do sistema político. Nesse contexto, segundo Napolitano, os mesmos garantiam uma rotina de decisões autocráticas ao mesmo tempo em que fornecia um amparo jurídico na tutela da sociedade civil e do sistema político.

7 A Lei da Imprensa, nesse contexto, foi utilizada para institucionalizar e regular a liberdade de expressão, servindo para impor limites aos profissionais da área. Além de consolidar o regime autoritário.

8 A Constituição de 1967 torna as eleições indiretas, além de facultar ao próprio Presidente da República a possibilidade de propor emendas constitucionais.
} 
assessoria política, partidária no que se refere à defesa do regime e pessoal com relação à defesa das manobras do mandatário.

\subsection{Atuação no Governo Geisel (“A Eminência Parda”)}

Golbery se tornou o primeiro e principal colaborador de Ernesto Geisel durante seu governo. Foi o chefe do Gabinete Civil durante seu mandato e por decorrência disso praticamente todas as decisões e negociações passavam por ele. Foi considerado a eminência parda ${ }^{9}$ desse governo. Luiz Alves (2011) associa à figura e postura de Golbery a definição de intelectual de Bobbio, afirmando que ele é um pensador que circula pelos chamados "corredores do poder", ou seja, pelo governo e dessa forma participa da vida pública. Alguns estudiosos (como Marcos Napolitano) trazem à tona a discussão sobre uma possível classificação do governo de Geisel como sendo uma "democracia relativa"10.

Muitos intérpretes - como Elio Gaspari11 - apontam para o papel central que Golbery desempenhou no processo de distensão do regime militar, construindo de certa maneira uma saída "suave" do regime, o que acabou desencadeando na chamada abertura. Geisel, nessa visão, também é considerado o presidente que se colocou - junto com Golbery - de maneira frontalmente contrária à chamada linha-dura ${ }^{12}$, derrotando-a. Segundo essa interpretação, o regime havia se desviado de suas intenções maiores, da manutenção da ordem, para produzir uma verdadeira anarquia comandada pelos insubordinados dos quartéis. Seria preciso reconstruir a institucionalidade política brasileira, eliminando os exageros do regime. É importante notar que o governo de Ernesto Geisel é

\footnotetext{
${ }^{9}$ Eminência parda é um assessor ou conselheiro e que atua nos "bastidores" de um governo, numa condição não pública ou não oficial - o que não era o caso dele, diga-se de passagem, já que era o chefe da Casa Civil.

10 O termo "democracia relativa" refere-se grosso modo ao fato de que o Brasil caminhava a passos largos rumo a uma abertura política, além de derrubar alguns atos e decretos os quais retiravam direitos civis essenciais para a vida política - porém, é importante observar que a derrubada desses atos não significou a extinção de tais atividades, sendo assim, por muito tempo ficou-se apenas na esfera institucional.

${ }^{11}$ Muitos autores enquadram Gaspari no posicionamento revisionista. O mesmo possui uma explicação baseada nos argumentos utilizados pelos próprios golpistas/ditadores, reproduzindo falas do aparato repressivo que colocavam a repressão como uma resposta à luta armada. Além disso, Elio Gaspari possui uma proposta interpretativa de um encurtamento da ditadura, a qual passa de 24 anos para 11. Essa análise desconsidera os períodos de 1964 a 1968 alegando que não se havia uma ditadura de forma plena, e o período de 1979 a 1988, argumentando que tal época é atravessada pelo processo de transição, desconsiderando um regime plenamente ditatorial.

12 Durante o período da ditadura civil-militar, os militares eram classificados entre "moderados" ou "linha-dura", na segunda classificação estavam os considerados mais radicais. Porém, tal classificação perdeu o sentido após a comprovação de que todos os governos desse período praticavam atrocidades - tortura, censura, etc -, inclusive, comprovou-se que do começo ao fim as práticas foram as mesmas, e que mesmo no processo de "abertura" política, tais abusos continuavam acontecendo.
} 
composto de inúmeras contradições, as quais segundo Napolitano seriam definidas como uma "estratégia clara de reforçar a autoridade do Estado e, consequentemente, dotar o regime e o governo de instrumentos para conduzir a transição para o governo civil com mão de ferro" (NAPOLITANO, 2014, p.231).

A princípio o processo de distensão - o qual por inúmeros motivos que serão tratados a seguir, culminou num processo de abertura política - foi um projeto de institucionalização do regime militar. Segundo Lamounier (2005), subtendia-se a necessidade de superar a rigidez para se chegar a uma estabilidade fundamentada mais na política e na aquiescência social do que na força das armas e dos aparelhos repressivos. Além disso, o autor analisa que no lado político reconhecia-se a necessidade de mudanças, porém essas mudanças deveriam ser controladas e graduais, segundo uma agenda e dentro dos limites definidos pelo governo. Nesse sentido, não era uma reforma, mas uma autorreforma do regime militar. O governo de Geisel tinha como objetivo preparar o terreno para a revogação do AI-5 e avançar no projeto de institucionalização A distensão possuía como objetivo afastar o risco de superisolamento, uma vez que a rigidez autoritária não estava mais sendo aceitável e nem sustentável. A autorreforma do regime seria realizada através de três medidas: revitalização da política, liberalização da imprensa e, contenção dos excessos cometidos por órgãos de segurança e repressão.

O governo de Geisel não foi ameno no que diz respeito à censura e repressão, Napolitano em seu livro contabiliza 39 opositores desaparecidos e 42 mortos pela repressão. Além disso, a censura à imprensa, artes e diversões foi amplamente utilizada, amenizando apenas em meados de 1976. O Congresso Nacional ficou fechado por cerca de 15 dias.

Contrariando o que se era falado sobre o desconhecimento em relação aos crimes cometidos, documentos recentes expostos pelos arquivos da CIA/ Estados Unidos, demonstram uma forte conexão entre os presidentes Ernesto Geisel e João Baptista Figueiredo e a execução de opositores do regime militar no período da chamada abertura gradual. O historiador Marcos Napolitano, em uma entrevista ao Jornal da USP (2018), afirma que se deve realizar uma revisão do lugar que Geisel ocupou da história do Brasil, para que assim se consolide outra memória - mais concreta e verdadeira - desse jogo entre distensão e abertura democrática. Além disso, o historiador comenta o quão problemático é ter que recorrer a documentos de outros países, mesmo depois de tanto tempo, para que 
se possa realizar uma revisão e uma reabertura sobre o que foi consolidado no passado acerca desse período. O jornal El País - Brasil afirma que o documento revelado pelo Bureau of Public Affairs do Departamento de Estado dos EUA demonstra que a cúpula do governo militar brasileiro sabia sobre as ações realizadas, ou seja, sobre as execuções dos adversários. O documento foi colocado na íntegra pelo portal G1-Globo, e afirma que o presidente brasileiro Ernesto Geisel decidiu que em determinadas situações devia-se continuar a execução sumária de subversivos perigosos. Essa decisão foi tomada conjuntamente com o último presidente militar, João Baptista Figueiredo, que era na época chefe do Serviço Nacional de Informações (SNI), com os Generais Milton Tavares de Souza, e Confúcio Danton de Paula Avelino, chefes do Centro de Informações do Exército (CIE).

\subsection{Atuação e renúncia no Governo Figueiredo}

Golbery do Couto e Silva continuou assumindo seu cargo de chefe da Casa Civil durante o governo de João Baptista Figueiredo, com quem possuía uma relação conturbada no que diz respeito à ação/posicionamento político. Tal governo iniciou seu mandato com a ilustre e árdua tarefa de reorganizar os suportes políticos para a autorreforma do regime militar, já iniciada durante o governo de seu antecessor, o general Ernesto Geisel. Nesse contexto, era necessária a formação de um novo partido capaz de manter uma efetiva interlocução com o governo e quiçá encerrar a ação dos aparelhos repressivos. Porém o que se obteve com a sucessão do general Geisel pelo general Figueiredo foi uma inconclusão no diz respeito aos caminhos seguidos pelos governantes do Brasil no que se refere ao processo de distensão/abertura ${ }^{13}$ e recondução do país a uma plenitude democrática. Segundo os pesquisadores do Projeto Brasil: Nunca Mais ${ }^{14}$,

A posse do general Figueiredo - escolhida como data-limite do período pesquisado no Projeto BNM - ocorre em 15 de março de 1979, num quadro em que a crise econômica se agrava e as modificações constitucionais legadas por Geisel criam brechas para o crescimento das pressões democráticas (PROJETO BNM, 1985, p.68).

\footnotetext{
13 É durante o governo de João Baptista Figueiredo que a distensão recebe o nome de "abertura". Essa mudança é consequência de uma forte pressão das ruas e de diversas instituições contrárias aos acontecimentos e ao governo. 14 O Projeto Brasil: Nunca Mais estudou a repressão exercida pelo Regime Militar a partir de documentos produzidos pelas próprias autoridades, apresentando como fontes as cópias de quase todos os processos políticos que transitaram pela Justiça Militar brasileira entre abril de 1964 e março de 1979.
} 
Como dito anteriormente, tal projeto de distensão - pensado durante o governo de Ernesto Geisel, e tendo como importante colaborador o Golbery do Couto e Silva não foi bem-sucedido na prática e se transformou posteriormente em uma agenda de transição democrática - a longo prazo - e que acabaria culminando na chamada abertura democrática. Essa mudança não foi fruto (como defendem alguns pesquisadores como Elio Gaspari) exclusivo e prioritário das intenções e conduções do palácio, ou seja, do governo. Muito pelo contrário, os militares não tinham intenção de sair dos postos ocupados, mas como dito anteriormente, realizar uma autorreforma. Nesse contexto, tal mudança na condução dos rumos políticos do Brasil apresenta como atores políticos importantes a pressão das ruas e dos movimentos sociais, o próprio sistema político, a Ordem dos Advogados do Brasil

Segundo Lamounier (2005) as demandas da oposição - as quais apresentavam fortes impactos nesse período - exigiam a anistia a todos os cidadãos punidos com cassação ou perda de direitos políticos e aos exilados por terem participado de ações armadas, além de exigir o reestabelecimento praticamente total da liberdade de imprensa. A parcial “adoção" dessas demandas ocorre entre os anos de 1978 e 1979, o que acaba reforçando a expectativa da população brasileira de que o país estaria caminhando para um rápido e inequívoco restabelecimento da democracia. Porém o que se obteve foi uma lenta e gradual "abertura controlada" sob a tutela dos militares, além de uma agenda política voltada à transição democrática. O debate colocado em questão no período era a retirada dos militares do chamado "coração do Estado", por esse motivo foi necessária a agenda política que construiria um processo gradual da normalização da vida pública.

Além disso, Napolitano (2014) trata da questão de como foi tratada a luta pela democracia, uma vez que foi consagrada a imagem de que os movimentos sociais voltaram a ser atores na luta pela democracia apenas após a abertura ser desencadeada, tal imagem supõe que a abertura foi uma decisão inequívoca do governo, um projeto uniforme de movimento histórico retilíneo, o qual teria permitido a expressão da contestação política e social. Essas questões errôneas que foram colocadas sobre o período da ditadura militar são consequências da falta de acesso a documentos do período - pelos mesmos serem colocados como inexistentes ou sigilosos-, além da anistia ser colocada como uma anistia universal e irrestrita - inviabilizando a responsabilização dos militares pelos crimes cometidos, somando-se a essas duas questões está à reconstrução tardia do período através 
de uma Comissão Nacional da Verdade implantada após aproximadamente 20 anos do final da ditadura militar, o que a tornou de certa modo "ineficiente".

A relação entre Golbery e o general Figueiredo começou a definhar após surtos de terrorismo serem atribuídos a grupos da extrema-direita e a remanescentes ativos dos aparelhos repressivos, e culmina na renúncia do mesmo ao cargo em 1981. Jornais da época demonstram que Golbery - ministro do Gabinete Civil da Presidência - enviou no dia 04 de julho de 1981 uma nota confidencial ao então presidente, que afirma não ter recebido a carta. O conteúdo do documento demonstra uma acusação de que os chamados DOICODIs estavam infiltrados de terroristas, e cobra do Planalto o seu desmanche. Trechos do documento demonstram:

Tudo indica que o IPM, não divulgado ainda, mas do qual a nota dada à imprensa pelo encarregado - bem lançada, aliás - parece dar ideia satisfatória, substanciará as conclusões finais de ter havido crime na área de competência da Justiça Militar, mas de não existirem elementos suficientes à indicação dos culpados (...). Verdade indiscutível é que um grupo radical, minoritário apenas, irresponsável e adepto de práticas terroristas - (...) - se não dominou ou controla, pelo menos infiltra os órgãos "vulgarmente chamados DOI-CODI", e, desde aí, acoberto dessas organizações e valendo-se, assim, de grandes facilidades e larga soma de poder, desencadeou ações terroristas múltiplas obedecendo a linhas hierárquicas distintas das legais e legítimas e que se estendem não se sabe até que níveis superiores dos escalões governamentais. (Silva apud JORNAL ZERO HORA - Segunda-feira, 21.09.87, p. 18).

Golbery termina sua nota confidencial afirmando que medidas devem ser tomadas a partir de tais acontecimentos, enfatizando que a autoridade do governo, além de sua credibilidade estava em jogo. O presidente Figueiredo parece ter ignorado tais questões e se mostrou negligente ao não exigir uma investigação mais rigorosa sobre o atentado, essa atitude ao que tudo indica acarretou na renúncia de Golbery - decisão formalizada em agosto de 1981, o que, segundo alguns intérpretes, gerou uma certa insegurança, já que “a ausência de Golbery, substituído pelo jurista gaúcho Leitão de Abreu, produziu um hiato na coordenação política do governo e criou apreensões sobre uma eventual reorientação da política de abertura" (LAMOUNIER, 2005, pp. 172). 


\section{Conclusão}

Golbery do Couto e Silva foi um ator/ importante no contexto dos preparativos do golpe de 1964 e durante a Ditadura Civil-Militar Brasileira. Após a análise de sua influência na posição ativa de ator político, mas também como civil e intelectual, com escritos relevantes e que se difundiram pelo mundo, em especial pela América Latina. Constata-se que investigar o pensamento desse autor permitiu uma análise sobre as bases teóricas do regime militar. Além de seu pensamento, investigar a ação desse ator político permitiu também perceber os pressupostos teóricos em que o Regime Militar se apoiou, se ancorou e se propagou.

Golbery iniciou sua carreira no âmbito militar em 1927, ao ingressar na Escola Militar de Realengo e, ao longo de sua trajetória construiu uma carreira notória. Ascendeu rapidamente na patente militar, indo de Tenente-Coronel em 1951, a Coronel em 1956 e finalmente a General em 1962. Sua participação em órgãos importantes, somados a sua grande influência no âmbito intelectual o colocou como um dos ideólogos do golpe. Sua atuação no período ditatorial de 1964 não se restringiu aos preparativos e ideologia, como foi visto ao longo deste trabalho, Golbery teve feitos importantes durante três governos: Castelo Branco, Ernesto Geisel e João Baptista Figueiredo.

\section{Referências}

\section{Fontes documentais}

ARQUIVO NACIONAL. Criação do Serviço Nacional de Informações e de seus órgãos: leis, decretos, decretos-lei e portarias. 10.janeiro. 1990

JORNAL CP. Figueiredo não recebeu carta, Porto Alegre/RS, 22.setembro.1987. (Documento retirado do Arquivo Nacional).

JORNAL DA USP. Documento da CIA realoca Geisel na história brasileira, São Paulo, 17.maio.2018. Disponível em: <https://jornal.usp.br/atualidades/docu mento-da-cia-realoca-geisel-na-historiabrasileira/>. Acesso em: 17.maio.2018.

JORNAL EL PAÍS. Documento da CIA relata que cúpula do Governo militar brasileiro autorizon execuções, São Paulo, 10.maio.2018. Disponível em: https://brasil.elpais.com/brasil/2018/05 /10/politica/1525976675975787.html. Acesso em: 10.maio.2018.

JORNAL OPINIÃO. (1974). As ideias políticas de Golbery do Couto e Silva; $\mathrm{n}^{\mathrm{0}} 70$. 
JORNAL ZERO HORA. Golbery denunciou terrorismo do DOI-CODI a Figueiredo, Porto Alegre/RS, 21.setembro.1987, pp. 18. (Documento retirado do Arquivo Nacional).

PORTAL G1-GLOBO. Em memorando, diretor da CIA diz que Geisel autorizon execução de opositores durante ditadura, 10.maio.2018. Disponível em: https://g1.globo.com/google/amp/polit ica/noticia/em-memorando-diretor-dacia-diz-que-geisel-autorizou-execucao-deopositores-durante-ditadura.ghtml.> Acesso em: 10.maio.2018.

\section{Referências bibliográficas}

ALVES, Luiz Felipe Nunes de. O bruxo e o feiticeiro: José López Rega e Golbery do Couto e Silva e o nacionalismo conservador no cone sul. Revista Expedições: Teoria da História \& Historiografia - número 03, 2011.

BONFADA, Thiago. Geopolitica brasileira e relações internacionais nos anos 50: o pensamento do general Golbery do Couto e Silva. Brasília: Fundação Alexandre de Gusmão, 2010.

CAFARELLI, Andressa Patacho. O pensamento politico de Golbery do Couto e Silva. Projeto de Iniciação Científica - PIBIC. Unifesp. São Paulo. 2017.

CALIL, Gilberto Grassi. "Revisionismo e embates em torno da memória: a abordagem de Elio Gaspari sobre a repressão e a resistência à ditadura brasileira”. In: Violência política no século XX: Um Balanço" (coord. FERREIRA, A.S; MADEIRA, J; CASANELLAS, P). Lisboa: Instituto de História Contemporânea, 2017.

CERVO, Amado. História da política exterior do Brasil. Brasília: Editora Universidade de Brasília, 2012.
DREIFUSS, René Armand. 1964: A conquista do Estado - ação politica, poder e golpe de classe. Rio de Janeiro: Editora Vozes Ltda, 1981.

FAVERZANI, Alex. Geopolitica do Brasil: a trajetória de Golbery do Couto e Silva e sua perspectiva no campo intelectual. Vitória: Revista Ágora, 2005.

FERNANDES, Amanda Simões. A reformulação da Doutrina de Segurança Nacional pela Escola Superior de Guerra no Brasil: a geopolitica de Golbery do Couto e Silva. Revista Antíteses, vol.2, n.4, jul-dez de 2009; 2009.

FERREIRA, Oliveiros da Silva. Forças Armadas para quê? Rio de Janeiro: Editora GRD, 1988.

FICO, Carlos; Versões e controvérsias sobre 1964 e a ditadura militar. São Paulo: Revista Brasileira de História, vol.24, n.47; 2004.

FICO, Carlos; O grande irmão: da operação Brother Sam aos anos de chumbo. Rio de Janeiro: Editora Civilização Brasileira, 2008.

GASPARI, Elio. A ditadura envergonhada: as ilusões armadas. São Paulo: Companhia das Letras, 2002.

GASPARI, Elio. A ditadura derrotada: o sacerdote e o feiticeiro. São Paulo: Companhia das Letras 2003.

KUNHAVALIK, José Pedro. Os militares e o conceito de nacionalismo: disputas retóricas na década de 1950 e o início dos anos 1960. Santa Catarina: UFSC, 2009.

LAMOUNIER, Bolívar. O processo politico durante o regime militar (1964-1985). In: Da Independência a Lula: dois séculos de política brasileira. São Paulo: Editora Augurium, 2005. 
NAPOLITANO, Marcos. História do regime militar brasileiro. São Paulo: Editora Contexto, 2014.

PROJETO BNM. O sistema repressivo. In: Brasil: nunca mais. Rio de Janeiro: Editora Vozes Ltda, 1985.

SÁ DE COSTA, Frederico Carlos de. (s/d). Repensando Golbery. Centro de Pesquisas Estratégicas Paulino Soares de Sousa. Universidade Federal de Juiz de Fora. Documento acessado em: http://www.ecsbdefesa.com.br/fts/Gol bery.pdf

SILVA, Golbery do Couto e; Planejamento Estratégico. Brasília: Editora Universidade de Brasília, 1981.

SILVA, Golbery do Couto e; Conjuntura política nacional: o poder executivo \& geopolitica do Brasil. Rio de Janeiro: Editora Jose Olympio, 1981.

VIEIRA, Fernando de Oliveira. O discurso anticomunista nos boletins mensais do Ipês entre 1963-1966. Dissertação de Mestrado defendida no PPG em Ciências Sociais da Unifesp. São Paulo, 2016. 